\title{
PENGEMBANGAN MEDIA PEMBELAJARAN POWER POINT MATA PELAJARAN ILMU PENGETAHUAN SOSIAL KELAS VII SEMESTER 1 DI SEKOLAH MENENGAH PERTAMA NEGERI 20 MALANG
}

\author{
Dinna Eka Graha Lestari \\ Program Studi Pendidikan Sejarah dan Sosiologi, \\ IKIP Budi Utomo Malang \\ dynna_lestari@yahoo.com
}

\begin{abstract}
Abstrak
Dunia Pembelajaran pada era sekarang ini mengalami kemajuan yang sangat pesat. Guru harus pandai pandai tanggap akan kemajuan yang ada khususnya dalam dunia pendidikan. Teknologi sangat berperan penting terhadap bidang pendidikan. Maka dari itu guru harus menciptakan inovasi-inovasi yang baru. Salah satunya adalah penggunaan power point ini. Media Pembelajaran Power point sangat penting dalam dunia pendidikan, diharapkan dengan menggunakan power point siswa tidak mengantuk, tidak jenuh dan bersemangat terhadap pelajaran yang diberikan oleh guru. Dengan menggunakan media pembelajaran power point guru juga lebih mudah menyampaikan materi, menjelaskan dengan sejelas-jelasnya, dalam waktu juga lebih efisien, demikian juga dengan siswa akan termotivasi lebih baik lagi. Tujuan dalam penelitian ini adalah yang pertama membantu guru dalam proses belajar mengajar dalam rangka mencapai tujuan pembelajaran yang telah ditetapkan, yang kedua sebagai media yang dapat menarik siswa dalam kegiatan belajar sehingga siswa dapat termotivasi. Metode penelitian yang dipergunakan dalam penelitian pengembangan media power point ini adalah menggunakan metode kuantitatif dimana data adalah berupa angka dan pengukurannya jg berupa angka. Lokasi penelitian yaitu di SMP Negeri 20 Malang. Hasil penelitiannya yaitu di temukan perbedaan antara siswa yang tidak pernah menggunakan media power point dengan siswa yang mempergunakan media power point setiap hari nya.
\end{abstract}

Kata Kunci: media, pembelajaran, pengembangan

\footnotetext{
Abstract

Audio visual media using the power point program is a learning resource that can be used as a learning medium in schools, especially in science subjects, the subject of grouping living things. Based on the
} 
results of observations made by developers at SMP Negeri 20 Malang, it turns out that the teacher only uses textbooks as the only learning medium. For this reason, developers make alternative problem solvers by developing power point media as a learning medium. The purpose of developing this power point media is to assist teachers in the teaching and learning process in order to achieve predetermined learning objectives. Also as a medium that can attract students' attention in learning activities so that students can be motivated. From the validation results show; 1) validation of media experts shows results of $80 \%, 2$ ) validation of material experts shows results of $93.75 \%, 3$ ) while in class validation shows results of $80.15 \%$ based on the above research shows that the power point which is developed has high validity.

Keywords: development, learning, media

\section{PENDAHULUAN}

Pendidikan merupakan sesuatu
yang pangat penting dalam
perkembangan sebuah bangsa, maka
lembaga pendidikan di Negara kita terus
berupaya mencari struktur kurikulum,
system pendidikan dan metode
pembelajaran yang efektif dan efisien
melalui pembaharuan maupun
eksperimen. Pembahasan tidak datang
dengan sendirinya, kita harus
mengupayakannya kalau tidak
pendidikan kita akan tertinggal oleh
perkembangan ilmu pengetahuan dan
tehnologi yang cepat ini. Pendidikan
kita dewasa ini menghadapi berbagai
macam tantangan, persoalan itu timbul
karena: 1 )bertambahnya jumlah
penduduk yang sangat cepat sekaligus

bertambahnya keinginan masyarakat untuk mendapat pendidikan yang secara komulatif menuntut tersedianya sarana pendidikan yang memadai, 2) berkembangnya ilmu pengetahuan yang modern menghendaki dasar dasar pendidikan yang kokoh dan penguasaan kemampuan terus menerus, dan dengan demikian menuntut pendidikan yang lebih lama sesuai dengan konsep pendidikan seumur hidup (long life education),3) berkembangnya tehnologi yang memudahkan manusia dengan menguasai dan memanfaatkan alam dan lingkungannya tetapi yang sering ditangani sebagai suatu ancaman terhadap kelestarian peranan manusiawi. Upaya mengoptimalkan kegiatan belajar, ternyata masih mengalami beberapa hambatan. Ada 
tiga hambatan dalam kegiatan pembelajaran $^{1}$ yaitu: 1. Hasil belajar siswa umumnya hanya sampai pada tingkat penguasaan yang merupakan hasil terendah. Siswa umumnya belajar dengan tehnik hafalan penjelasan guru atau dari buku buku, 2) Sumber yang digunakan siswa terbatas pada penjelasan guru dan sedikit dari buku buku pegangan (handbook), 3) dalam kegiatan belajar mengajar guru kurang merangsang aktifitas belajar siswa secara optimal, metode yang digunakan hanya terbatas pada ceramah dan Tanya jawab.

Dari ketiga hambatan diatas menunjukkan bahwa praktek praktek kegiatan pembelajaran masih belum optimal karena terkendala oleh tehnik menghafal guru. Selain itu kendala lain adalah pola pengajaran guru masik kurang memberikan rangsangan pada siswa karena terbatasnya metode dan kemampuan yang dimiliki oleh karena itu peranan media pembelajaran sangat diperlukan untuk membantu pengajaran guru. Pentingnya dilakukan pengembangan media power point mata pelajaran Ilmu Pengetahuan Sosial

\footnotetext{
${ }^{1}$ Sudirman (1987),
}

karena media audio visual ini merupakan salah satu factor penting untuk memudahkan pengajaran. Pengembangan media power point sudah sering dilakukan di kota kota besar karena ketersediaan saran dan prasarana. Walaupun seharusnya pengembangan media power point dapat digunakan oleh siapapun tanpa mengenal batas wilayah baik didaerah maupun di perkotaan. Penggunaan media atau alat bantu dalam proses belajar mengajar bertujuan mempertinggi prestasi belajar siswa pada umumnya. Pentingnya dilakukan pengembangan media power point mata pelajaran Ilmu Pengetahuan Sosial sebagai alternative untuk memecahkan masalah diatas, pengembangan media power point merupakan salah satu factor penting untuk:1) menarik perhatian siswa terhadap materi pelajaran yang disajikan, 2) meningkatkan pengertian siswa terhadap materi pelajaran yang disampaikan, 3) menyajikan data, menguatkan informasi dan memudahkan dalam mengumpulkan dan mengolah data, 4) memberikan pengalaman yang jelas kepada siswa terhadap materi pelajaran yang 
disampaikan, 5) supaya materi yang disampaikan dapat diingat dengan baik oleh siswa.

\section{METODE PENELITIAN}

Beberapa langkah yang perlu diperhatikan dalam menyusun media yaitu: 1)membuat ide,2) merumuskan tujuan,3) mempertimbangkan audience, 4)menetapkan kerangka isi, 5)merencakan partisipasi audience, 6) menentukan pembentukan tim produksi, 7) menulis synopsis,8) menyusun naskah, 9) mempertimbangkan waktu, 10) merencanakan pelaksanaan, 11) editing, 12) evaluasi program. ${ }^{2}$ Prosedur pengembangan media di atas maka dalam menyusun pengembangan media power point ini dapat dilakukan melalui kegiatan berikut:

1. Analisis kebutuhan

Kegiatan pertama yang dilakukan dalam pengembangan media power point ini adalah melakukan kajian lapang untuk mengetahui bagaiman kondisi kegiatan pembelajaran yang dilakukan di SMP Negeri 20 Malang. Tujuannya adalah untuk mendapatkan masukan tentang karakteristik siswa, model pembelajaran dan media apa saja yang digunakan dalam proses belajar mengajar di SMP Negeri 20 Malang.

2. Analisis Tujuan

Kegiatan selanjutnya adalah melakukan analisis tujuan yang telah diidentifikasi untuk mengetahui pengetahuan yang hendak dicapai. Analisis ini didasarkan pada Tujuan Instruksional Umum (TIU)

3. Mengembangkan materi

Berdasarkan analisis tujuan pembelajaran maka materi yang dikembangkan adalah mata pelajaran Ilmu Pengetahuan Sosial untuk siswa kelas VII semester 1.

4. Menyusun naskah

Berdasarkan pada identifikasi tujuan dan kajian materi pada buku panduan mengajar maka disusunlah naskah pengembangan media power point.

\section{Produksi}

\footnotetext{
${ }^{2}$ Abidin dan Susulaningsih (1990:28)
} 
Setelah selesai menyusun naskah, penyusunan petunjuk penggunaan selanjutnya melakukan kegiatan produksi pengembangan media power point yang merupakan inti dari kegiatan pengembangan.

6. Menyusun petunjuk pemanfaatan Kegiatan ini dilakukan agar para pemakai media power point (guru dan siswa) dapat memanfaatkan media ini dengan tepat dan sesuai dengan petunjuk pemanfaatan.

7. Validasi individual (ahli media, ahli materi, uji coba siswa secara individual, uji coba kelompok (berupa uji coba kekelompok kecil) dan uji coba lapangan (uji coba kelas)

Kegiatan validasi bertujuan untuk mengumpulkan data sebagai dasar untuk menetapkan apakah media pembelajarn ini layak digunakan dalam kegiatan pembelajaran serta apakah media yang dibuat dapat digunakan untuk mencapai tujuan pembelajaran yang ditetapkan.
8. Revisi

Revisi dilakukan dengan menyempurnakan media power point apabila ternyata belum memenuhi criteria yang diharapkan setelah melakukan validasi ahli media, ahli materi dan audience/siswa.

\section{Instrumen Pengumpulan Data}

Data dalam pengembangan media power point ini menggunakan instrument berupa angket. Penggunaan angket dalam mengumpulkan data adalah karena semua objek dapat membaca dan memahami isi dengan mudah, memberikan kesempatan untuk berfikir cermat dan teliti kepada responden untuk mempelajari isi yang terdapat dalam angket

Tehnik Analisis Data

Pengolahan data merupakan salah satu langkah yang sangat berarti dalam kegiatan pengembangan media power point ini. Teknis analisis data dalam pengembangan media power point ini termasuk dalam penelitian data kuantitatif. Adapun rumus yang 
digunakan dalam mengelola data dikelompokkan menjadi dua yang pertama adalah rumus untuk mengolah data tanggapan ahli media, ahli materi, dan tanggapan audiens atau siswa. Yang kedua adalah rumus untuk mengolah data soal pre test dan post test.

\section{HASIL DAN PEMBAHASAN}

Pada bagian penyajian data ini akan diuraikan data hasil validasi yang diperoleh dari ahli media, ahli materi dan responden audien/siswa kelompok kecil dan klasikal. Data validasi ahli media diperoleh dari dua orang ahli media pembelajaran, data validasi ahli materi diperoleh dari dua orang ahli materi mata pelajaran Ilmu Pengetahuan Sosial (IPS) dan data validasi kelompok kecil berjumlah 5 orang dan data validasi klasikal berjumlah 33 orang. Dari data validasi yang diperoleh dapat diketahui hasil pengembangan dari ahli media, ahli materi dan audiens/siswa yang selanjutnya akan dianalisis validitasnya dengan menggunakan rumus:

$\mathrm{P}=\frac{\sum X}{\sum X i} \times 100 \%$

Keterangan:

P : Prosentase $\sum \mathrm{X}$ : Jumlah keseluruhan jawaban responden dalam seluruh item

$\sum X \mathrm{X}$ : Jumlah Keseluruhan nilai ideal dalam satu item

$100 \%$ : Konstanta

Untuk menentukan kesimpulan hasil yang telah dicapai maka ditetapkan criteria sebagai berikut:

Tabel 1 Kriteria validitas media Power point

\begin{tabular}{|l|l|}
\hline \multicolumn{1}{|c|}{ Prosentase } & \multicolumn{1}{c|}{ Kriteria } \\
\hline $80 \%-100 \%$ & Valid \\
$60 \%-79 \%$ & Cukup Valid \\
$50 \%-59 \%$ & Kurang valid atau \\
& revisi \\
$<50 \%$ & $\begin{array}{l}\text { Tidak valid atau } \\
\text { diganti }\end{array}$ \\
\hline
\end{tabular}

Untuk mengetahui perbedaan hasil belajar siswa sebelum menggunakan media power point dalam pembelajaran (pre test) dengan setelah menggunakan media power point (post test) adalah dengan menggunakan uji $t$ seperti dibawah ini:

$\mathrm{t}=\frac{M d}{\sqrt{\frac{\sum \times 2 \mathrm{~d}}{\mathrm{~N}(\mathrm{~N}-1)}}}$

Keterangan:

Md : Mean dari perbedaan pre test dan post test

$\mathrm{Xd} \quad$ : deviasi masing masing subjek (d-Md) 
$\sum \mathrm{X}^{2} \mathrm{~d}$ : Jumlah kuadrat deviasi

$\mathrm{N} \quad$ : Subjek pada sampel

$\mathrm{Db} \quad$ : ditentukan dengan N-1

Penyajian data dan analisis Data Hasil validasi produk

1. Menyajian data ahli media

Variabel yang menjadi aspek pengamatan tentang kualitas media power point pembelajaran menurut penilaian ahli media dapat disajikan dalam bentuk table berikut:

Tabel 2: Daftar Nama dan hasil angket ahli media

Hasil Validasi tentang kualitas media power point oleh ahli media adalah sebagai berikut:

Tabel 3: Pengolahan data ahli media

\begin{tabular}{|c|c|c|c|c|c|c|}
\hline $\begin{array}{l}\mathrm{N} \\
\mathrm{O}\end{array}$ & Item/Aspek & \begin{tabular}{l|l}
$\mathrm{S}$ \\
$\mathrm{k}$ \\
$\mathrm{O}$ \\
$\mathrm{r}$
\end{tabular} & \begin{tabular}{c|c}
$X$ & $X$ \\
1 & 2
\end{tabular} & $\mid \begin{array}{l}\sum \\
X\end{array}$ & $\begin{array}{l}\sum \\
\mathrm{X} \\
\mathrm{i}\end{array}$ & $\%$ \\
\hline 1 & $\begin{array}{l}\text { Ketepatan } \\
\text { Penentuan } \\
\text { media power } \\
\text { point sebagai } \\
\text { media untuk } \\
\text { menyampaik } \\
\text { an materi }\end{array}$ & & \begin{tabular}{l|l}
44 & 3
\end{tabular} & 7 & 8 & $87,5 \%$ \\
\hline \begin{tabular}{|l|} 
\\
\\
.
\end{tabular} & $\begin{array}{l}\text { Kesesuaian } \\
\text { bahasa yang } \\
\text { pdgunakan } \\
\text { dengan } \\
\text { karakteristik } \\
\text { pebelajar }\end{array}$ & & \begin{tabular}{l|l}
3 & 4
\end{tabular} & 7 & 8 & $87,5 \%$ \\
\hline \begin{tabular}{|c|}
3 \\
$B^{\circ}$
\end{tabular} & \begin{tabular}{|l} 
Kejelasan \\
suara penyaji \\
pada waktu \\
penyampaian \\
materi
\end{tabular} & & \begin{tabular}{l|l}
2 & 4
\end{tabular} & 6 & 8 & $75 \%$ \\
\hline 4 & $\begin{array}{l}\text { Kesesuaian } \\
\text { panggunaan } \\
\text { music baik } \\
\text { music } \\
\text { Aembuka, } \\
\text { selingan } \\
\text { maupun } \\
\text { music } \\
\text { penutup }\end{array}$ & & \begin{tabular}{l|l}
4 & 3
\end{tabular} & 7 & 8 & $87,5 \%$ \\
\hline 5 & $\begin{array}{l}\text { Kesesuaian } \\
\text { tempo dan } \\
\text { kecepatan } \\
\text { penyajian } \\
\text { media power } \\
\text { point dengan }\end{array}$ & & \begin{tabular}{l|l}
2 & 3
\end{tabular} & 5 & 8 & $62,5 \%$ \\
\hline
\end{tabular}




\begin{tabular}{|c|c|c|c|c|c|c|}
\hline & $\begin{array}{l}\text { tingkat } \\
\text { penerimaan } \\
\text { siswa }\end{array}$ & & & & & \\
\hline 6 & $\begin{array}{l}\text { Kualitas } \\
\text { suara dan } \\
\text { gambar } \\
\text { dalam } \\
\text { penayangan } \\
\text { materi }\end{array}$ & 4 & 2 & 6 & 8 & $75 \%$ \\
\hline 7 & $\begin{array}{l}\text { Kesesuaian } \\
\text { gambar } \\
\text { dengan } \\
\text { materi yang } \\
\text { disampaikan }\end{array}$ & 3 & 3 & 6 & 8 & $75 \%$ \\
\hline 8 & $\begin{array}{l}\text { Kemenarikan } \\
\text { animasi } \\
\text { gambar } \\
\text { dengan } \\
\text { penyajian } \\
\text { materi }\end{array}$ & 3 & 4 & 7 & 8 & $87,5 \%$ \\
\hline 9 & $\begin{array}{l}\text { Keserasihan } \\
\text { perpaduan } \\
\text { antara music, } \\
\text { suara penyaji } \\
\text { dan gambar }\end{array}$ & 3 & 3 & 6 & 8 & $75 \%$ \\
\hline $\begin{array}{l}1 \\
0\end{array}$ & $\begin{array}{l}\text { Keutuhan } \\
\text { penyajian } \\
\text { program dari } \\
\text { awal sampai } \\
\text { akhir }\end{array}$ & 3 & 4 & 7 & 8 & $87,5 \%$ \\
\hline & Jumlah & & & $\begin{array}{l}6 \\
4\end{array}$ & $\begin{array}{l}8 \\
0\end{array}$ & $80 \%$ \\
\hline
\end{tabular}

Keterangan:

X1 : Jumlah jawaban responden 1 (Dr Dedi Kuswandi., M.Pd)

X2 : Jumlah jawaban responden 2 (Drs. Eko Pramono Adi. S.Pd., M.Si) $\sum \mathrm{x} \quad$ : Jumlah Keseluruhan jawaban responden dalam seluruh item

$\sum \mathrm{Xi}$ : Jumlah keseluruhan nilai ideal dalam satu item

Rumus :

$\mathrm{P}=\frac{\sum X}{\sum X 1} \times 100 \%=0,8=80 \%=$ Valid

Dari hasil validitas yang dilakukan terhadap ahli media diatas di peroleh hasil $80 \%$. Berdasarkan criteria yang telah ditentukan dapat dikatakan bahwa media power point pada anak kelas VII semester 1 valid dan layak digunakan dalam proses belajar mengajar.

Penyajian data ahli materi

Variabel yang menjadi aspek pengamatan tentang kualitas media power point pembelajaran menurut penilaian ahli materi dpat disajikam dalam bentuk table berikut:

Tabel 4 Daftar nama dan hasil angket ahli materi

\begin{tabular}{|l|l|l|l|l|l|l|l|l|l|l|l|}
\hline $\mathrm{N}$ & $\mathrm{A}$ & 1 & 2 & 3 & 4 & 5 & 6 & 7 & 8 & 9 & 1 \\
$\mathrm{a}$ & $\mathrm{s}$ & & & & & & & & & & 0 \\
$\mathrm{~m}$ & $\mathrm{p}$ & & & & & & & & & \\
\hline
\end{tabular}




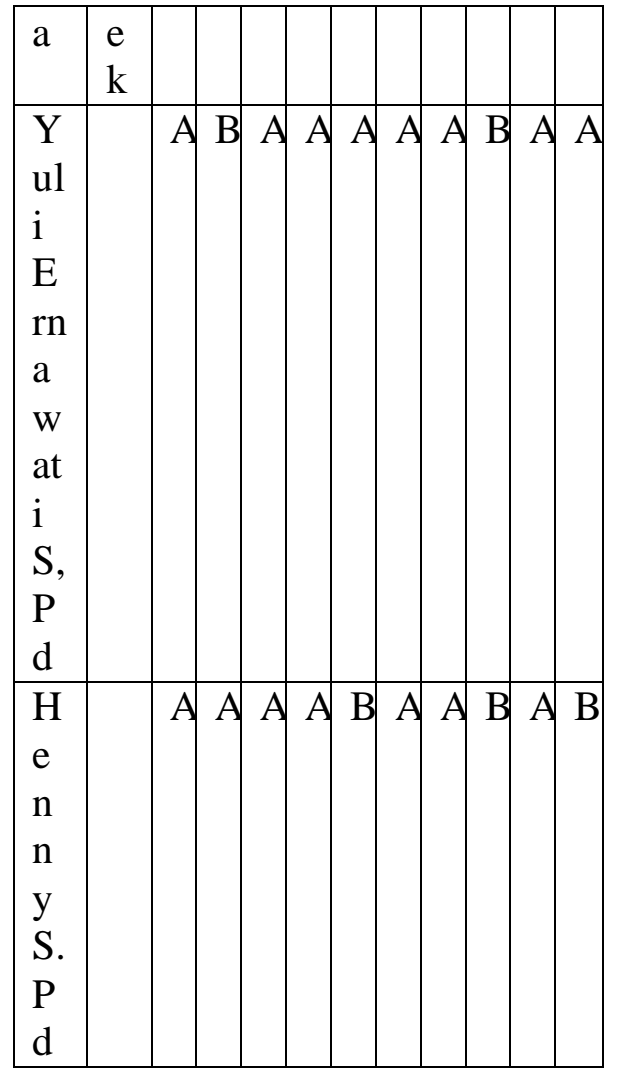

Hasil validasi tentang kualitas media power point oleh ahli materi adalah sebagai berikut:

Tabel 5 Pengolahan data ahli materi

\begin{tabular}{|c|c|c|c|c|c|c|}
\hline \multirow{2}{*}{$\begin{array}{l}\mathrm{N} \\
\mathrm{O}\end{array}$} & \multirow[t]{2}{*}{ Item/Aspek } & \multicolumn{5}{|c|}{ Skor } \\
\hline & & $\begin{array}{l}X \\
1\end{array}$ & $\begin{array}{l}X \\
2\end{array}$ & & $\begin{array}{l}\sum \\
\mathrm{X} \\
\mathrm{i}\end{array}$ & $\%$ \\
\hline 1. & \begin{tabular}{l}
\multicolumn{3}{l}{ Kesesuaian } \\
cakupan materi \\
dengan \\
yang \\
dirumuskan \\
\end{tabular} & 4 & 4 & 8 & 8 & $\begin{array}{l}10 \\
0 \%\end{array}$ \\
\hline 2. & $\begin{array}{l}\text { Kesesuaian } \\
\text { format gambar } \\
\text { yang digunakan } \\
\text { untuk } \\
\text { memperjelas } \\
\text { penyampaian }\end{array}$ & 3 & 4 & 7 & 8 & $\begin{array}{l}87, \\
5 \%\end{array}$ \\
\hline
\end{tabular}

\begin{tabular}{|c|c|c|c|c|c|c|}
\hline & materi & & & & & \\
\hline 3. & $\begin{array}{l}\text { Kemenarikan } \\
\text { materi yang } \\
\text { disampaikan }\end{array}$ & 4 & 4 & 8 & 8 & $\begin{array}{l}10 \\
0 \%\end{array}$ \\
\hline 4. & $\begin{array}{l}\text { Sistematika/urut } \\
\text { as isi materi }\end{array}$ & 4 & 4 & 8 & 8 & $\begin{array}{l}10 \\
0 \%\end{array}$ \\
\hline 5. & $\begin{array}{l}\text { Keefektifan } \\
\text { dalam } \\
\text { penyampaian } \\
\text { materi }\end{array}$ & 4 & 3 & 7 & 8 & $\begin{array}{l}87 \\
5 \%\end{array}$ \\
\hline 6. & $\begin{array}{l}\text { Materi yang } \\
\text { disampaikan } \\
\text { dapat } \\
\text { memotifasi } \\
\text { siswa dalam } \\
\text { belajar }\end{array}$ & 4 & 4 & 8 & 8 & $\begin{array}{l}10 \\
0 \%\end{array}$ \\
\hline 7. & \begin{tabular}{l}
\multicolumn{2}{l}{ Pengorganisasia } \\
$\mathrm{n}$ penyajian \\
materi melalui \\
media audio \\
visual hasil \\
pengembangan \\
dari program \\
power point
\end{tabular} & 4 & 4 & 8 & 8 & $\begin{array}{l}10 \\
0 \%\end{array}$ \\
\hline 8. & $\begin{array}{l}\text { Kesesuaian } \\
\text { bahasa dan } \\
\text { gambar dengan } \\
\text { karakteristik } \\
\text { siswa }\end{array}$ & 3 & 3 & 6 & 8 & $\begin{array}{l}75 \\
\%\end{array}$ \\
\hline 9. & $\begin{array}{l}\text { Kesesuaian } \\
\text { waktu } \\
\text { penayangan } \\
\text { dengan materi } \\
\text { yang } \\
\text { disampaikan }\end{array}$ & 4 & 4 & 8 & 8 & $\begin{array}{l}10 \\
0 \%\end{array}$ \\
\hline $\begin{array}{l}1 \\
0 .\end{array}$ & $\begin{array}{l}\text { Strategi dalam } \\
\text { penyampaian } \\
\text { materi }\end{array}$ & 4 & 3 & 7 & 8 & $\begin{array}{l}87, \\
5 \%\end{array}$ \\
\hline & Jumlah & & & 5 & $\begin{array}{l}8 \\
0\end{array}$ & $\begin{array}{l}93 \\
75 \\
\%\end{array}$ \\
\hline
\end{tabular}

Keterangan: 
$\mathrm{X} 1$ : Jumlah jawaban responden 1 (Yuli Ernawati S.Pd)

X2 : Jumlah jawaban responden 2 (Henni S,Pd)

$\sum \mathrm{X}$ : Jumlah keseluruhan jawaban responden dalam seluruh item

$\sum \mathrm{Xi}$ : Jumlah keseluruhan nilai ideal dalam satu item

Rumus:

$\mathrm{P}=\frac{\sum X}{\sum X i} \times 100 \%=0,9375=$ $93,75 \%=$ Valid

Dari hasil validasi yang dilakukan terhadap ahli media diatas diperoleh hasil 93,75\%. Berdasarkan criteria yang telah ditentukan dapat dikatakan bahwa media power point dengan pokok bahasan pengelompokan mahluk hidup termasuk dalam criteria valid dan layak digunakan dalam proses belajar mengajar.

Penyajian data audiens/ siswa

Uji coba kelompok kecil

Data hasil uji coba kelompok kecil disajikan dalam bentuk berikut:

Tabel 6 Daftar hadir angket uji coba kelompok kecil

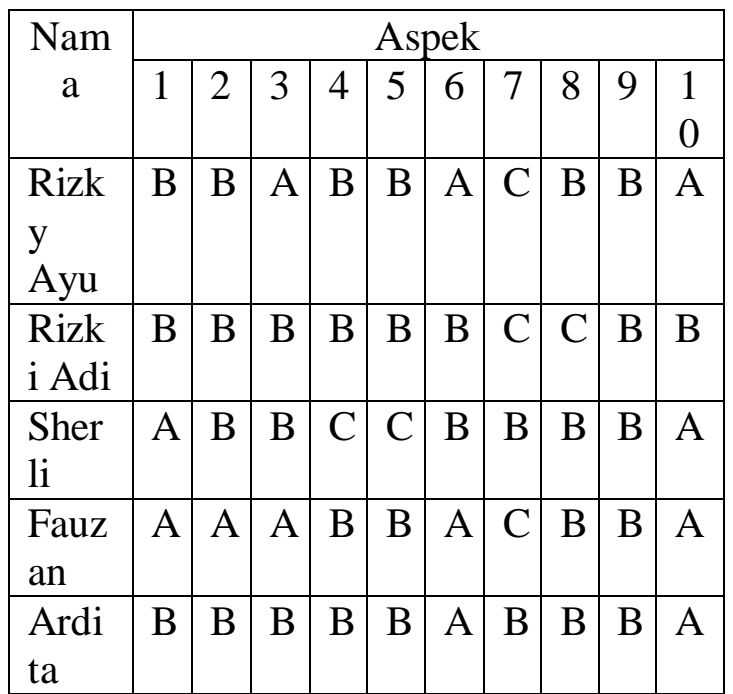

Hasil validari tentang kualitas media power point oleh kelompok kecil adalah sebagai berikut:

Tabel 7 Pengolahan data hasil angket Uji coba kelompk kecil

\begin{tabular}{|c|c|c|c|c|c|c|c|c|c|}
\hline \multirow[b]{2}{*}{$\begin{array}{l}\mathrm{N} \\
\mathrm{O}\end{array}$} & \multirow[b]{2}{*}{$\begin{array}{l}\text { Item/ } \\
\text { Aspek }\end{array}$} & \multicolumn{8}{|c|}{ Skor } \\
\hline & & $\begin{array}{c}X \\
1\end{array}$ & $\begin{array}{l}X \\
2\end{array}$ & $\begin{array}{l}X \\
3\end{array}$ & $\begin{array}{l}X \\
4\end{array}$ & $\begin{array}{l}X \\
5\end{array}$ & $\begin{array}{l}\sum_{X} \\
X\end{array}$ & $\begin{array}{c}\sum \\
X \\
i\end{array}$ & $\%$ \\
\hline 1 & $\begin{array}{l}\text { Mendapat } \\
\text { kan } \\
\text { pengetahu } \\
\text { an baru }\end{array}$ & 3 & 3 & 4 & 4 & 3 & $\begin{array}{l}1 \\
7\end{array}$ & $\begin{array}{l}2 \\
0\end{array}$ & $85 \%$ \\
\hline 2 & $\begin{array}{l}\text { Memberi } \\
\text { semangat } \\
\text { atau } \\
\text { memotivas } \\
\text { i dalam } \\
\text { belajar }\end{array}$ & 3 & 3 & 3 & 4 & 3 & $\begin{array}{l}1 \\
6\end{array}$ & $\begin{array}{l}2 \\
0\end{array}$ & $80 \%$ \\
\hline 3 & $\begin{array}{l}\text { Memberik } \\
\text { an variasa } \\
\text { dalam } \\
\text { belajar }\end{array}$ & 4 & 3 & 3 & 4 & 3 & $\begin{array}{l}1 \\
7\end{array}$ & $\begin{array}{l}2 \\
0\end{array}$ & $85 \%$ \\
\hline 4 & $\begin{array}{l}\text { Materi } \\
\text { yang } \\
\text { disampaik } \\
\text { an mudah } \\
\text { diingat }\end{array}$ & 3 & 3 & 2 & 3 & 3 & $\begin{array}{l}1 \\
4\end{array}$ & $\begin{array}{l}2 \\
0\end{array}$ & $70 \%$ \\
\hline
\end{tabular}




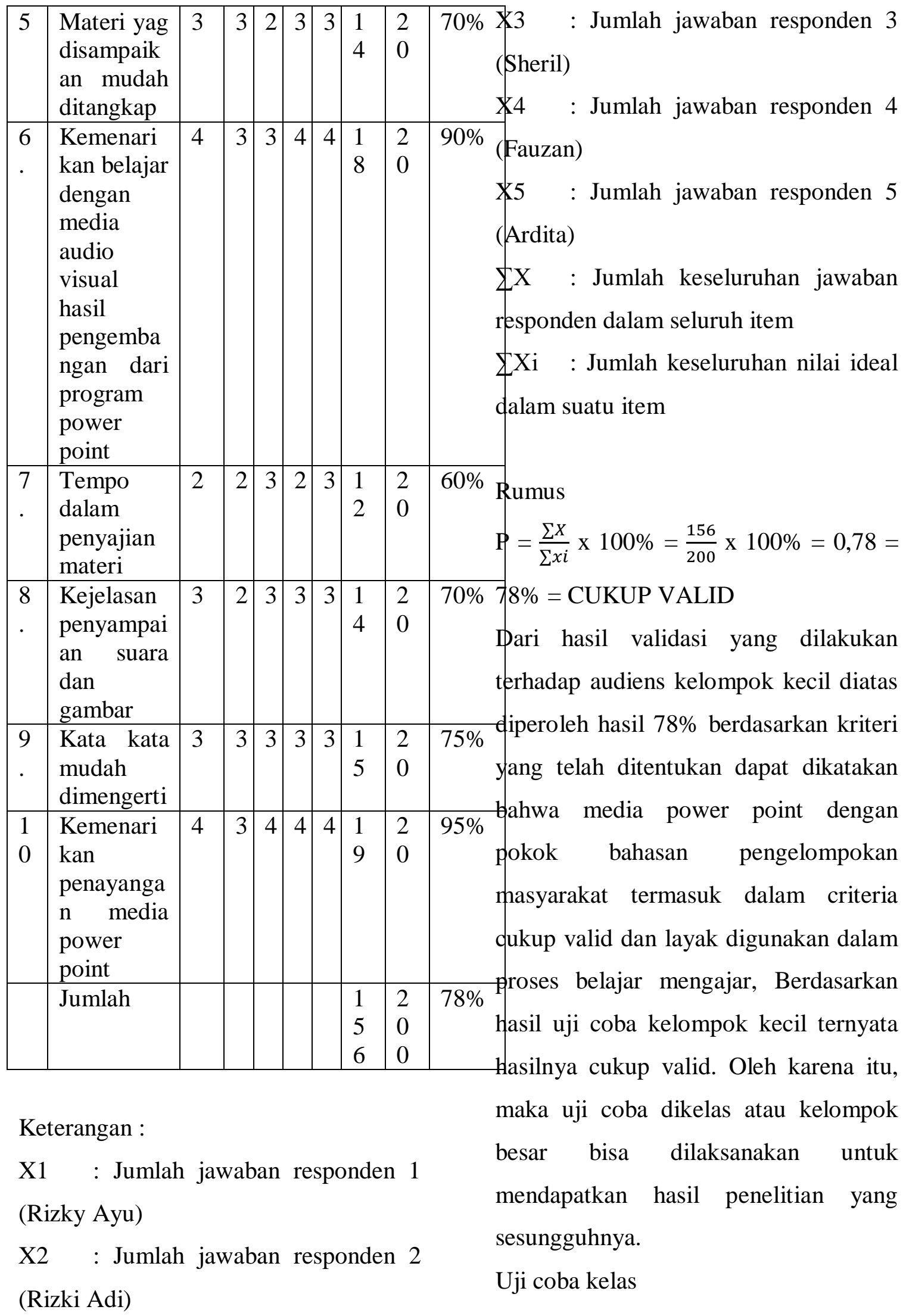


Data hasil uji coba lapangan (uji coba

Kelas) disajikan dalam bentuk table berikut:

Tabel 8 Daftar Hasil angket Uji coba kelas

\begin{tabular}{|c|c|c|c|c|c|c|c|c|c|c|}
\hline \multirow{2}{*}{ Nama } & \multicolumn{10}{|c|}{ Aspek } \\
\hline & 1 & 2 & 3 & 4 & 5 & 6 & 7 & 8 & $y$ & 10 \\
\hline Sefti & & & $\mathbf{1}$ & B & $\mathrm{A}$ & A & A & B & B & $\mathrm{Ac}$ \\
\hline Dinc & & & B & B & $\mathrm{B}$ & A & A & B & B & $A$ \\
\hline Dest & & $B$ & 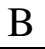 & B & B & A & B & B & Bv & $A_{x}$ \\
\hline Aide & & & A & B & $\mathrm{A}$ & $\mathrm{A}$ & A & A & A & $\mathrm{A}^{1}$ \\
\hline Ade & & E & B & $B$ & $\mathrm{C}$ & $B$ & $\mathrm{C}$ & $\mathrm{C}$ & D. & $\mathrm{B}_{3}^{4}$ \\
\hline Bis & & & B & B & $\mathrm{B}$ & A & $\mathrm{C}$ & B & C. & $\mathrm{A}_{3}^{4}$ \\
\hline Ded & & T & B & $\mathrm{C}$ & $\mathrm{C}$ & $B$ & $\mathrm{C}$ & $\mathrm{B}$ & $\mathrm{B}^{5}$ & $\mathrm{~A}_{4}^{4}$ \\
\hline $\begin{array}{l}\text { Herlam } \\
\text { ang }\end{array}$ & & & A & $\mathrm{C}$ & $\mathrm{C}$ & $\mathrm{C}$ & $\mathrm{C}$ & A & B. & $\mathrm{B}_{3}^{4}$ \\
\hline Saiful & & $\underline{\mathrm{F}}$ & 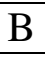 & $\mathrm{B}$ & $\mathrm{B}$ & $\mathrm{B}$ & $\mathrm{B}$ & B & C & A \\
\hline Eko & & & A & $\mathrm{B}$ & $\mathrm{B}$ & $\mathrm{A}$ & $\mathrm{C}$ & $\mathrm{B}$ & $\mathrm{Bv}_{\mathrm{v}}$ & $\overline{A_{x}}$ \\
\hline $\begin{array}{l}\text { Kurn } \\
\text { an }\end{array}$ & & B & B & $\mathrm{C}$ & $\mathrm{C}$ & B & $\mathrm{C}$ & $\mathrm{C}$ & $C^{3}$ & $A_{1}^{2}$ \\
\hline Noval & & & D & B & $\mathrm{B}$ & A & B & B & A & $\mathrm{A}_{3}^{3}$ \\
\hline $\mathrm{He}$ & & & t & A & $\mathrm{B}$ & A & A & A & B. & $A_{2}^{3}$ \\
\hline $\begin{array}{l}\text { Rar } \\
\text { ani }\end{array}$ & & A & A & A & $\mathrm{A}$ & A & $\mathrm{C}$ & A & B. & $\mathrm{A}_{3}^{3}$ \\
\hline Gh & & & & A & $\mathrm{B}$ & A & $\mathrm{C}$ & B & $1 /$ & $A^{3}$ \\
\hline Rizk & & & B & $\mathrm{B}$ & $\mathrm{B}$ & A & $\mathrm{D}$ & B & B & A \\
\hline $\mathrm{Pu}$ & & & & $\mathrm{B}$ & $\mathrm{B}$ & $\mathrm{A}$ & $\mathrm{A}$ & $\mathrm{B}$ & $\mathrm{B}$ & $\mathrm{A}$ \\
\hline $\mathrm{Alz}$ & & A & B & $B$ & $\mathrm{~A}$ & $\mathrm{~A}$ & $\mathrm{~A}$ & $\mathrm{~A}$ & $B$ & $\mathrm{Ar}$ \\
\hline Rif & & & & B & $\mathrm{C}$ & B & B & B & B & \\
\hline Wa & & & & B & $\mathrm{B}$ & A & A & $\mathrm{C}$ & B & \\
\hline Ima & & & B & B & $\mathrm{B}$ & A & A & $\mathrm{C}$ & B & $\mathrm{A}^{3}$ \\
\hline Tri & & & & B & $\mathrm{B}$ & B & $\mathrm{B}$ & B & $\mathrm{B}$ & \\
\hline Palt & & E & A & B & $\mathrm{B}$ & B & A & B & $\mathrm{B}$ & $\mathrm{A}^{2}$ \\
\hline $\mathrm{Nin}$ & & & & $\mathrm{B}$ & $\mathrm{B}$ & $\mathrm{A}$ & $\mathrm{A}$ & $\mathrm{B}$ & $\mathrm{A}$ & $\mathrm{A}^{\mathrm{d}}$ \\
\hline Vir & & $\mathrm{F}$ & A & B & $\mathrm{B}$ & A & A & B & A & A \\
\hline Inta & & $\mathrm{B}$ & B & $\mathrm{C}$ & $\mathrm{B}$ & $\mathrm{B}$ & $\mathrm{B}$ & $\mathrm{C}$ & $\mathrm{C}$ & \\
\hline & & & & $\mathrm{C}$ & $\mathrm{C}$ & $B$ & $B$ & $\mathrm{C}$ & $\mathrm{B}$ & $\mathrm{A}^{\mathrm{C}}$ \\
\hline Em & & A & 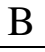 & B & $\mathrm{C}$ & B & B & B & B & $\mathrm{A}_{1}$ \\
\hline $\begin{array}{l}\text { Fauziatu } \\
1\end{array}$ & B & B & B & B & $\mathrm{C}$ & B & B & B & B & $\mathrm{A}$ \\
\hline Kurnia & & & 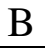 & $\mathrm{C}$ & $\mathrm{B}$ & A & $\mathrm{D}$ & $\mathrm{C}$ & $\mathrm{C}$ & A \\
\hline Anind & A & B & A & B & $\mathrm{B}$ & A & A & B & B & A \\
\hline
\end{tabular}

\begin{tabular}{|l|l|l|l|l|l|l|l|l|l|l|}
\hline Mia & B & B & B & A & A & A & A & C & B & A \\
\hline Gita & A & B & A & B & B & A & D & B & B & A \\
\hline
\end{tabular}

Hasil Validasi tentang kualitas media power point uji coba kelas adalah sebagai berikut:

Tabel 9 Pengolahan data hasil angket uji kelas

\begin{tabular}{|c|c|c|c|c|c|c|c|c|c|c|c|c|c|}
\hline \multicolumn{1}{|c|}{} \\
$\mathrm{X}$ & & $\mathrm{X}$ & $\mathrm{X}$ & $\mathrm{X}$ & $\mathrm{X}$ & $\mathrm{X}$ & $\mathrm{X}$ & $\mathrm{X}$ & $\mathrm{X}$ & $\mathrm{X}$ & $\mathrm{X}$ & $\mathrm{X}$ & $\mathrm{X}$ \\
2 & $\mathrm{X} 3$ & 4 & 5 & 6 & 7 & 8 & 9 & 1 & 1 & & 1 & 1 \\
& & & & & & & & & 1 & 2 & 3 & 4 & \\
4 & 4 & 3 & 3 & 3 & 2 & 4 & 3 & 3 & 4 & 4 & 4 & 4 & 3 \\
3 & 3 & 4 & 3 & 3 & 3 & 4 & 3 & 3 & 3 & 4 & 4 & 4 & 3 \\
3 & 3 & 4 & 3 & 3 & 3 & 4 & 3 & 4 & 3 & 3 & 4 & 4 & 4 \\
3 & 3 & 3 & 3 & 3 & 2 & 2 & 3 & 3 & 2 & 3 & 4 & 4 & 4 \\
3 & 3 & 4 & 2 & 3 & 2 & 2 & 3 & 3 & 2 & 3 & 3 & 4 & 3 \\
4 & 4 & 4 & 3 & 4 & 3 & 2 & 3 & 4 & 3 & 4 & 4 & 4 & 4 \\
3 & 3 & 4 & 2 & 2 & 2 & 2 & 3 & 2 & 2 & 3 & 4 & 2 & 2 \\
3 & 3 & 4 & 2 & 3 & 3 & 4 & 3 & 3 & 2 & 3 & 4 & 4 & 3 \\
3 & 3 & 4 & 1 & 2 & 3 & 3 & 2 & 3 & 2 & 4 & 3 & 3 & 4 \\
4 & 4 & 4 & 3 & 4 & 4 & 3 & 4 & 4 & 4 & 4 & 4 & 2 & 4 \\
\hline
\end{tabular}

\begin{tabular}{|l|l|l|l|l|l|l|l|l|l|l|l|l|}
\hline & $X$ & $X$ & $X$ & $X$ & $X$ & $X$ & $X$ & $X$ & $X$ & $X$ & $x$ & $X$ \\
\hline
\end{tabular} 
3. Member variasi dalam belajar

4. Materi yang disampaikan mudah diingat

5. Materi yang disampaikan mudah ditangkap

6. Kemenarikan belajar dengan menggunakan media power point

7. Tempo dalam penyajian materi

8. Kejelasan penyampaian suara dan gambar

9. Kata kata mudah dimengerti

10. Kemenarikan penayangan media power point

Rumus

$\mathrm{P}=\frac{\sum x}{\sum x} \mathrm{x} 100 \%=\frac{1058}{1320} \times 100 \%=0,8015$ $=80,15 \%=$ VALID

Dari hasil validasi yang dilakukan terhadap kelompok besar atau dikelas diperoleh hasil 80,15\%. Berdasarkan criteria yang telah ditentukan, hasil ini menunjukkan bahwa pengembangan media power point dengan pokok bahasan pengelompokan masyarakat termasuk dalam criteria yang valid dan layak digunakan dalam proses belajar mengajar

Analisis Data

Berdasarkan table 3 hasil validasi ahli media dapat dianalisis sebagai berikut:
1. Ketepatan penentuan media power sebagai media untuk menyampaikan materi adalah $87,5 \%$ (sangat tepat)

2. Kesesuaian bahasa yang digunakan dengan karakteristik pembelajaran adalah $87,5 \%$ (sangat sesuai)

3. Kejelasan suara penyajian pada waktu penyampaian materi adalah $75 \%$ (jelas)

4. Kesesuaian penggunaan music baik music pembuka, selingan maupun music penutup adalah $87,5 \%$ (sangat sesuai)

5. Kesesuaian tempo atau kecepatan media power point dengan tingkat penerimaan siswa adalah $62,5 \%$ (sesuai)

6. Kualitas suara dan gambar dengan metri yang disampaikan adalah $75 \%$ (bagus)

7. Kesesuaian gambar dengan materi yang disampaikan adalah $75 \%$ (sesuai)

8. Kemenarikan animasi gambar dalam penyajian materi adalah $87,5 \%$ (sangat menarik)

9. Keserasihan antara suara music, suara penyaji dan gambar adalah $75 \%$ (serasi) 
10. Keutuhan penyajian program dari awal sampai akhir adalah $87,5 \%$ (utuh)

Berdasarkan table 5, hasil validasi ahli materi dapat dianalisis sebagai berikut:

a. Kesesuaian cakupan materi dengan TIK yang dirumuskan adalah $100 \%$ (sangat sesuai)

b. Kesesuaian format gambar yang digunakan untuk memperjelas penyampaian materi adalah $87,5 \%$ (sangat sesuai)

c. Kemenarikan materi yang disampaikan adalah $100 \%$ (sangat menarik)

d. Sistematika atau urutan isi materi adalah $100 \%$ (sangat bagus)

e. Keefektifan dalam penyampaian materi adalah $87,5 \%$ (sangat efektif)

f. Materi yang disampaiakn dapat memotivasi siswa dalam belajar adalah $\quad 100 \% \quad$ (sangat memotivasi)

g. Pengorganisasian penyajian materi melalui media power point adalah $100 \%$ (sangat teratus) h. Kesesuaian bahasa dengan gambar dengan karakteristik siswa adalah $75 \%$ (sesuai)

i. Kesesuaian waktu penayangan dengan materi yang disampaikan adalah $100 \%$ (sangat tepat)

j. Strategi dalam penyampaian materi adalah $87,5 \%$ (sangat terstruktur)

Berdasarkan table 7 hasil validasi kelompok kecil dapat dianalisis sebagai berikut:

a. Mendapat pengetahuan baru adalah $85 \%$ (sangat banyak)

b. Memberi semangat atau memotivasi dalam belajar adalah $80 \%$ (sangat member motivasi)

c. Memberikan variasi dalam belajar adalah $85 \%$ (sangat member variasi)

d. Materi yang disampaikan mudah diingat adalah $75 \%$ (dapat diingat)

e. Materi yang disampaikan mudah ditangkap adalah 70\% (dapat diterima)

f. Kemenarikan belajar dengan menggunakan media power point adalah $90 \%$ (sangat menarik) 
g. Tempo dalam penyajian materi adalah 60\% (kadang cepat, kadang lambat)

h. Kejelasan penyampaian suara dan gambar adalah $70 \%$ (jelas)

i. Kata kata mudah dimengerti adalah $75 \%$ (dapat dimengerti)

j. Kemenarikan penayangan media power point adalah $95 \%$ (menarik)

Berdasarkan table 9, hasil validasi di kelas atau kelompok besar dapat dianalisis sebagai berikut :

a. Mendapatkan pengetahuan baru $85,6 \%$ (sangat banyak)

b. Member semangat atau memotivasi dalam belajar adalah $80.3 \%$ (sangat member motivasi)

c. Memberikan variasi dalam belajar adalah $84,84 \%$ (sangat member variasi)

d. Materi yang disampaiak mudah diingat adalah $73,48 \%$ (dapat diingat)

e. Materi yang disampaiakn mudah ditangkap adalah 71,96\% (dapat diterima)

f. Kemenarikan belajar dengan menggunakan media power point adalah $89,39 \%$ sangat menarik

g. Tempo dalam penyajian materi adalah $72,72 \%$ (dalam cepat kadang lambat)

h. Kejelasan penyampaian suara dan gambar adalah $72,72 \%$ (jelas)

i. Kata kata mudah dimengerti adalah $\quad 72,72 \% \quad$ (dapat dimengerti)

j. Kemenarikan penayangan media power point adalah $97,72 \%$ (menarik)

\section{Pengujian Hasil Belajar Siswa}

Berdasarkan hasil yang diperoleh siswa pada evaluasi baik sebelum menggunakan media power point maupun sesudah menggunakan media power point, selanjutnya dilakukan perbandiang untuk mengetahui apakah ada perbedaan hasil belajar siswa sebelum menggunakan media power point (pre test) dan sesudah menggunakan media power point (post test). Berikut table data hasil belajar siswa. Hasil belajar pre test dan post tes kelompok kecil (5 orang) adalah sebagai berikut: 
Tabel 10 Daftar Hasil Pre test dan post Test kelompok kecil

\begin{tabular}{|c|c|c|c|c|c|}
\hline $\begin{array}{c}\text { Sub } \\
\text { yek }\end{array}$ & $\begin{array}{c}\text { Pre } \\
\text { Test }\end{array}$ & $\begin{array}{c}\text { Post } \\
\text { Test }\end{array}$ & $\begin{array}{c}\text { Gai } \\
\mathrm{n}(\mathrm{d})\end{array}$ & $\begin{array}{c}\mathrm{Xd} \\
=(\mathrm{d} \\
- \\
\mathrm{Md}\end{array}$ & $\mathrm{X}^{2} \mathrm{~d}$ \\
\hline 1. & 67 & 93 & 26 & -6 & 36 \\
2. & 53 & 67 & 14 & -18 & 324 \\
3. & 47 & 80 & 33 & 1 & 1 \\
4. & 40 & 87 & 47 & 15 & 225 \\
5. & 33 & 73 & 40 & 8 & 64 \\
\hline $\mathrm{N}=$ & $\sum \mathrm{X}_{1}$ & $\sum \mathrm{X}_{2}$ & $\sum \mathrm{d}=$ & & $\sum \mathrm{X}^{2} \mathrm{~d}$ \\
5 & $=240$ & $=400$ & 160 & & $=650$ \\
\hline
\end{tabular}

$\mathrm{T}=\frac{M d}{\sqrt{\frac{\sum x 2 d}{N(N-1)}}}$

$\mathrm{T}=\frac{32}{\sqrt{\frac{650}{5(5-1)}}}=\frac{32}{\sqrt{\frac{650}{20}}}=5,61$

$\mathrm{T}_{\text {table }}(5,4)=2,78$

Oleh karena $t_{\text {hitung }}(5,61)>t_{\text {tabel }}(2,78)$ maka $\mathrm{H}_{1}$ diterima yang menunjukkan bahwa terdapat perbedaan antara siswa yang belajar sebelum menggunakan media power point. Dari hasil evaluasi belajar kelompok kecil dapat disimpulkan bahwa media power point telah efektif untuk digunakan sebagai media pembelajaran kelompok kecil. Sedangkan untuk hasil belajar pre test dan post test kelas (33 orang) adalah

\begin{tabular}{|c|c|c|c|c|c|}
\hline & & & & Md) & \\
\hline 1. & 67 & 67 & 0 & 31,7 & 1010,6 \\
\hline 2. & 73 & 80 & 7 & 9 & 614,54 \\
\hline 3. & 60 & 87 & 27 & 24,7 & 22,94 \\
\hline 4. & 47 & 87 & 40 & & 67,4 \\
\hline 5. & 47 & 93 & 46 & & 201,92 \\
\hline 6. & 73 & 93 & 20 & 4,79 & 139,01 \\
\hline 7. & 40 & 73 & 33 & 8,21 & 1,46 \\
\hline 8. & 47 & 80 & 33 & 14,2 & 1,46 \\
\hline 9. & 53 & 93 & 40 & 1 & 67,4 \\
\hline 10. & 60 & 100 & 40 & 11,7 & 67,4 \\
\hline 11. & 53 & 80 & 27 & 9 & 22,94 \\
\hline 12. & 53 & 80 & 27 & 1,21 & 22,94 \\
\hline 13. & 53 & 93 & 40 & 1,21 & 67,4 \\
\hline 14. & 47 & 73 & 26 & 8,21 & 22,94 \\
\hline 15. & 47 & 87 & 40 & 8,21 & 67,4 \\
\hline 16. & 60 & 87 & 27 & & 22,94 \\
\hline 17. & 53 & 60 & 7 & 4,79 & 614,56 \\
\hline 18. & 60 & 87 & 27 & & 22,94 \\
\hline 19. & 40 & 73 & 33 & 4,79 & 1,46 \\
\hline 20. & 40 & 60 & 20 & 8,21 & 139,01 \\
\hline 21. & 33 & 73 & 40 & & 67,40 \\
\hline 22. & 60 & 80 & 20 & 4,79 & 139,01 \\
\hline 23. & 73 & 100 & 27 & 8,21 & 22,94 \\
\hline 24. & 73 & 100 & 27 & & 22,94 \\
\hline 25. & 53 & 100 & 47 & 4,79 & 231,34 \\
\hline 26. & 33 & 100 & 76 & 24,7 & 3994,24 \\
\hline 27. & 47 & 80 & 33 & 9 & 1,46 \\
\hline 28. & 27 & 67 & 40 & & 67,40 \\
\hline 29. & 53 & 80 & 27 & 4,79 & 22,94 \\
\hline 30. & 33 & 93 & 60 & 1,21 & 795,8 \\
\hline 31. & 53 & 87 & 34 & 11,7 & 4,88 \\
\hline 32. & 40 & 87 & 47 & 9 & 231.34 \\
\hline \multirow[t]{18}{*}{33.} & 73 & 93 & 20 & 8,21 & 139,01 \\
\hline & & & & 11,7 & \\
\hline & & & & 10 & \\
\hline & & & & 4,79 & \\
\hline & & & & 4,79 & \\
\hline & & & & 15,2 & \\
\hline & & & & 1 & \\
\hline & & & & 63,2 & \\
\hline & & & & 1,21 & \\
\hline & & & & 8,21 & \\
\hline & & & & & \\
\hline & & & & $\begin{array}{r}4,19 \\
28 ?\end{array}$ & \\
\hline & & & & 1 & \\
\hline & & & & 22,2 & \\
\hline & & & & 1 & \\
\hline & & & & 15,2 & \\
\hline & & & & 117 & \\
\hline & & & & 9 & \\
\hline $\mathrm{N}=33$ & $\begin{array}{l}\sum \mathrm{X}_{1}=12 \\
74\end{array}$ & $\sum \mathrm{X}_{2}=277$ & $\sum \begin{array}{c}\sum \mathrm{d}=104 \\
9\end{array}$ & & $\begin{array}{c}\sum \mathrm{X}^{2} \mathrm{~d}=8939, \\
34\end{array}$ \\
\hline
\end{tabular}

sebagi berikut:

Tabel 11 Daftar hasil pre test dan post test Kelas

\begin{tabular}{|c|c|c|c|c|c|}
\hline $\begin{array}{c}\text { Subje } \\
\mathrm{k}\end{array}$ & Pre Test & $\begin{array}{c}\text { Post } \\
\text { Test }\end{array}$ & $\begin{array}{c}\text { Gain } \\
(\mathrm{d})\end{array}$ & $\begin{array}{c}\mathrm{Xd} \\
\mathrm{(d-}-\end{array}$ & $\mathrm{X}^{2} \mathrm{~d}$ \\
\hline
\end{tabular}

$$
\begin{aligned}
& \mathrm{T}=\frac{M d}{\sqrt{\frac{\sum \times 2 d}{N(N-1)}}} \\
& \mathrm{T}=\frac{31,79}{\sqrt{\frac{8939,34}{33(33-1)}}}=\frac{31,79}{\sqrt{\frac{8939,34}{1056}}}=10,92
\end{aligned}
$$


$\mathrm{T}_{\text {table }}(5,32)=2,04$

Oleh karena $t_{\text {hitung }}(10,92)>t_{\text {tabel }}(2,04)$

maka $\mathrm{H}_{1}$ diterima yang menunjukkan bahwa terdapat perbedaan antara siswa yang belajar sebelum menggunakan media power point dengan sesudah menggunakan media power point. Dari hasil evaluasi belajar kelas dapat disimpulkan bahwa media power point telah efektif untuk digunakan sebagai media pembelajaran kelas.

\section{SIMPULAN}

Media power point ini telah memenuhi criteria valid setelah diadakan validasi dan uji coba di antara nya: pada ahli media dengan hasil menunjukkan sebesar $80 \%$ dapat disimpulkan bahwa media power point efektif untuk digunakan sebagai media pembelajaran, pada ahli materi dengan hasil menunjukkan sebesar $93,75 \%$ dapat disimpulan bahwa materi yang disajikan dengan media power point efekti untuk digunakan sebagai media pembelajaran. Pada audiensi siswa kelompok kecil dengan hasil menunjukkan $78 \%$ dapat disimpulkan bahwa media power point cukup efektif untuk digunakan pada media pembelajaran pada kelompok kecil. Pada audience/siswa kelas/kelompok besar dengan hasil $80,15 \%$ dapat disimpulkan bahwa media power point efektif dapat digunkan sebagai media pembelajarn di kelas atau kelompok besar. Dari hasil valisadi dan uji coba yang telah dilakukan dapat disimpulkan bahwa media power point yang disajikan secara lebih variatif sehingga mampu merangsang minat siswa dalam mempelajari pelajaran IPS pokok pelajaran dalam pengelompokan masyarakat serta dapat digunakan sebagai alternative sumber belajar bagi siswa. Media power point juga dapat membantu guru dalam mencapai tujuan yang telah ditetapkan secara lebih efektif. Pada hasil belajar kelompok kecil dan besar, melalui pengujian hipotesis rumus statistic dapat diketahui bahwa $\mathrm{H}_{1}$ diterima $\mathrm{H}_{0}$ ditolak karena ada perbedaan antara siswa yg belajar sebelum menggunakan media power point. Meskipun terdapat beberapa kelebihan dengan adanya menggunakan media power point dibanding dengan metode ceramah tp dalam penayangan media ini dibutuhkan ruangan khusus untuk menayangkan media ini dan peralatan yang memadai untuk mendukungnya. 


\section{DAFTAR PUSTAKA}

Abidin, Z \& Susilaningsih. (1991). Media Audio Instruksional dan Tehnik Pembuatannya. Malang: IKIP Malang

Arikunto, S. (1998). Prosedur Penelitian: Suatu pendekatan Praktek. Jakarta: Renika Cipta

Ena, o. Membuat Media Pembelajaran Interaktif Dengan Piranti Lunak Presentasi. www.ialf.edu/keep bipa/oudatedaena. doc

Hamalik, O. (1989). Media Pendidikan. Bandung: Citra Aditya Bakti

Latuheru, J. D. (1988). Media Pembelajaran: dalam Proses Belajar Mengajar Masa Kini. Jakarta: Depdikbud.

Pardosi, M. (2004). Belajar Sendiri Microsoft Power Point 2000 secara cepat dan mudah. Surabaya: Indah Surabaya

Peraturan Pemerintah Republik Indonesia nomer 19 tahun 2005 tentang standart nasional Pendidikan. Jakarta: Biro hokum Sekjen Depdiknas

Percifal, F \& Elington, H. (1984). Teknologi Pendidikan. Terjemahan Oleh Soejarwo S.1988. Jakarta: Airlangga
Pribadi, B A. \& Rosito, T. (2005). Prospek Komputer sebagai media pembelajaran interaktif dalam system pendidikan jarak jauh di Indonesia. http//pk.ut.ac.id/jsi/82benny.ht $\mathrm{m}$

Rudiyanto, I. (2005). Kemampuan widyaiswara menggunakan program Microsoft power point di balai diklat pertanian nganjuk. Skripsi tidak diterbitkan. Malang: UM

Rusian, T. A, Kusdinar, A \& Arifin, Z. (1989). Pendekatan dalam proses belajar mengajar. Bandung: remaja karya offset

Sadiman, Arif S, dkk. (2002). Media pendidikan : Pengertian, pengembangan dan pemanfaatannya. Jakarta: Raja Grafindo persada

Setiyosari, P. (2001). Rancangan Pembelajaran. Malang: Elang Mas

Soemanto, W \& Soetopo, H. (1982). Dasar dan teori Pendidikan Dunia. Surabaya: Usaha Nasional

Soedirman. 1989. Ilmu Pendidikan. Bandung: Rajawali

Soedjana, N. (1990). Penilaian hasil proses belajar mengajar. Bandung: Remaja Rosdakarya. 